\title{
Complete nucleotide sequence of the 16S rRNA from Lactobacillus paracasei HS-05 isolated from women's hands
}

\author{
Woon Yong Choi ${ }^{1}$ and Hyeon Yong Lee $2^{2^{*}}$
}

\begin{abstract}
We determined the complete nucleotide sequence of the 16S rRNA from a new bacterium collected from the surfaces of women's hands. We also compared the presence of various bacteria based on the subjects' sex and age. The number of colonies isolated from the hand surface was larger for women than men, and the largest number of isolates was confirmed to be present for the women in their $30 \mathrm{~s}$ and men in their $40 \mathrm{~s}$ (147 and 34 isolates, respectively). The morphology of an isolated bacterial strain was found to be rod type, and the bacterium was identified as Lactobacillaceae species based on the GenBank database, through a phylogenetic analysis using the $16 \mathrm{~S}$ rRNA sequence. Based on the results of a homology search, the isolated strain was $99 \%$ identical to Lactobacillus paracasei, so it was designated Lactobacillus paracasei HS-05 and was registered in the Korea Culture Center of Microorganisms (KCCM) database as [KCCM11349P].
\end{abstract}

Keywords: Lactobacillus paracasei HS-05, Mitochondrial genome, Women's hand surface

\section{Introduction}

In addition to their use in fermenting milk products or natural substances, lactic acid bacteria have been reported to be able to perform other special activities, such as producing antibiotics (Lim et al. 2008). In addition, lactic acid bacteria are introduced into the intestines to improve the properties of the intestinal microflora, where they play beneficial roles in host animals, such as stabilization of the intestinal microflora, disease prevention by suppressing the settlement of harmful bacteria, immune activation, anticancer activity, and lowering the LDL cholesterol level (Cotter et al. 2005; Jack et al. 1995; Kojic et al. 1991; Maeng et al. 1997; Marie et al. 1996). Among the substances produced by lactic acid bacteria, bacteriocin is a natural antibiotic protein or proteinbased substance and is known to have effective germicidal activity against pathogenic microorganisms (Holo

\footnotetext{
*Correspondence: hyeonl@seowon.ac.kr

${ }^{2}$ Department of Food Science and Engineering, Seowon University,

Cheongju 361-742, Korea

Full list of author information is available at the end of the article
}

et al. 1991; Petersen et al. 2006; Schillinger and Lucke 1989; Todorov and Dicks 2005).

In addition to their applications in fermentation, lactic acid bacteria are being increasingly utilized in the cosmetics industry. Lactic acid bacteria fragments have shown antioxidant effects and whitening effects, and they increase the activity of cosmetic agents (Choi et al. 2013). However, to date, the lactic acid bacteria that have been used for cosmetics were those that were already in use in food fermentation, such as Lactobacillus rhamnosus, Lactobacillus paracasei, and Lactobacillus casei (Frederic and Vuyst 2004). Therefore, lactic acid bacteria that better fit the characteristics needed for the cosmetics industry should be identified to provide more effective activities.

The human skin contains numerous microorganisms, with the Propionibacterium, Streptococcaceae, Staphylococcaceae, and Lactobacillaceae known to exist in the largest numbers. Among these, Propionibacterium and Streptococcaceae have been reported to be predominant, with the Lactobacillaceae comprising a smaller population (Fierera et al. 2008). However, among the various human body parts, lactic acid bacteria (especially

\section{Springer}


Lactobacillaceae) are found in large numbers on the hands, and it has previously been shown that more lactic acid bacteria are present on women's hands than on men's hands (Fierera et al. 2008; Costello et al. 2009; Dong et al. 2011). If new human skin-derived lactic acid bacteria can be isolated and identified, they can be utilized in the development of natural food preservatives in the current probiotics market and as alternative medicines (to provide antibiotics), and moreover, these bacteria may be more appropriate for use in the cosmetics industry. Therefore, in the present study, a new human skin-derived Lactococcus paracasei strain, HS-05, was isolated, and its morphological characteristics were investigated. In addition, 16S rRNA sequencing was conducted to identify the microorganisms isolated from human hands.

\section{Materials and methods}

The isolation of a new bacterial strain from human hands

To isolate lactic acid bacteria from human skin, approximately 40 men and women in their teens to their $40 \mathrm{~s}$ were asked to participate in an experiment 7 days prior to the experiment being performed. The experiment was conducted on an unspecified day so the participants would not wash or treat their hands differently before the experiment (Fierera et al. 2008). The right palm of each participant was pressed on MRS Agar (288210, Difco, USA), which was made in advance to inoculate the culture medium with initial microorganisms, and the inoculated initial samples were cultivated for $48 \mathrm{~h}$ in $37{ }^{\circ} \mathrm{C}$ incubators using anaerobic gas packs (Gas Pak, BBL, USA). After the culture, the obtained microorganisms were dispensed by streaking with platinum loops on MRS Agar and were cultured under anaerobic conditions for $48 \mathrm{~h}$ in $37{ }^{\circ} \mathrm{C}$ incubators to obtain individual strains. Using the isolated lactic acid bacteria, the phylogenetic tree of the 16S rRNA sequences was analyzed (Baek et al. 2010). For more detail characterization of the bacterium, the changes of cell growth and $\mathrm{pH}$ in the medium were also measured according to the culture temperature since the temperature of the hands was mostly affected under conventional environments. First, the cultures of the bacterium were incubated at $25,30,37,40$ and $45^{\circ} \mathrm{C}$ for $24 \mathrm{~h}$. At the end of each incubation time, the counts of surviving cells were determined by plating on MRS agar. In addition, the $\mathrm{pH}$ (initial $\mathrm{pH}$ of the medium was 6.5) was also measured for $24 \mathrm{~h}$ cultivation by a $\mathrm{pH}$ meter (Sentron Titan pH meter) (Tomas et al. 2003).

\section{Analysis of the phylogenetic tree of the 16S rRNA sequences}

To compare the phylogenetic trees of the isolated bacteria, a 16S rRNA analysis was conducted using the iQ5 real-time PCR detection system (Bio-Rad Laboratories). The phylogenetic tree was generated through a molecular phylogenic analysis based on the 16S rRNA gene base sequences of the isolated strains. The primers used to amplify the16S rRNA genes were the 27F (5'-AGAGTTT GATCMTGGCTCAG-3') primer and 1492R (5'-TACG GYTACCTTGTTACGACTT-3') primer synthesized based on the conserved sequence of the E. coli $16 \mathrm{~S}$ rRNA gene. The RT-PCR was conducted by performing 33 cycles of denaturation $\left(94{ }^{\circ} \mathrm{C}, 30 \mathrm{~s}\right)$, annealing $\left(60{ }^{\circ} \mathrm{C}\right.$, $30 \mathrm{~s})$, and elongation $\left(72{ }^{\circ} \mathrm{C}, 45 \mathrm{~s}\right)$, followed by incubation for 15 min at $72{ }^{\circ} \mathrm{C}$ (Baek et al. 2010). After determining the 16S rRNA gene nucleotide sequences, each base sequence was compared with the base sequences of similar strains in the GenBank database to determine the phylogenetic locations of the strains (Baek et al. 2010).

\section{Scanning electron microscopy (SEM)}

To photograph the newly isolated bacterial strain, a lowvacuum scanning electron microscope (SEM) (XL 30, Philips, The Netherlands) was used at $400 \times$ magnification to observe the morphology of the bacteria. Sample slices were immersed in an $8 \%$ paraformaldehyde and $2.5 \%$ glutaraldehyde solution made using $0.05 \mathrm{M}$ sodium cacodylate buffer ( $\mathrm{pH}$ 7.2) and were fixed four $2 \mathrm{~h}$ at $4{ }^{\circ} \mathrm{C}$. The sample slices were washed three times for 2 min each time using $0.05 \mathrm{M}$ sodium cacodylate buffer ( $\mathrm{pH} 7.2)$ and were then fixed by treatment in a $1 \%$ osmium tetroxide solution for $2 \mathrm{~h}$ at $4{ }^{\circ} \mathrm{C}$, followed by two washes with tertiary distilled water at room temperature. The fixed samples were dehydrated in $30,50,70,80$, and $90 \%$ ethanol for 10 min each and in $100 \%$ ethanol three times for $10 \mathrm{~min}$ each time. After the dehydration, the samples were mounted on metal stubs by two transitions for $15 \mathrm{~min}$ using $100 \%$ propylene oxide and were then coated with gold using a sputter coater (Agar Scientific Ltd. SC502, USA). The samples were observed using a scanning electron microscope (Philips XL30E, USA) (Williams and Davies 1967).

\section{Results}

\section{Isolation and characteristics of a new bacterial strain}

Lactic acid bacteria were isolated by pressing the unwashed hands of men and women in their 10-40 s on MRS (de Man, Rogosa and Sharpe) agar culture medium. The numbers of each age of men and women (ages of 10, 20,30 and 40's) in the experiments were 25 and the mean averages of the colonies in the agar plates from each age were estimated after counting the colonies. The proband of all the examinees was varied such as secretaries, students, hard workers, and drivers, etc. and the terms of their jobs were also varied from less than 1-20 years, which should affect the bacterial profiles of their hands. 
The numbers of colonies obtained from the men and women were compared (not shown data). Based on the results, the average number of colonies of men in their teens was 56, and that of women in their teens was 51; further, that of men in their $20 \mathrm{~s}$ was 47 , and that of women in their $20 \mathrm{~s}$ was 77 . Although the number of colonies obtained from men in their $30 \mathrm{~s}$ dramatically decreased down to ca. 23, the number obtained from women in their $30 \mathrm{~s}$ was approximately 147 . In addition, the number of colonies from men in their $40 \mathrm{~s}$ was ca. 34, while the number from women in the same ages was decreased down to only 58 . Based on these results, we concluded that the number of colonies isolated from the hands of women tended to be higher than that isolated from men, and when the numbers of colonies were compared by age group, it was found that women in their $30 \mathrm{~s}$ had the largest number of colonies. A total of four subcultures from the colonies obtained from women were conducted on MRS Agar culture medium, and the bacteria that formed clear white colonies were selected. For further characterization of the bacterium, as shown in Fig. 1, optimal growth temperature was determined as $37{ }^{\circ} \mathrm{C}$, which is closed to human temperature, by showing that $6.7 \times 10^{6}$ viable $\mathrm{CFU} / \mathrm{mL}$ were observed after $12 \mathrm{~h}$ cultivation at $37^{\circ} \mathrm{C}$ while about $7.4-8.8 \times 10^{6} \mathrm{CFU} /$ $\mathrm{mL}$ of cell density were maintained for $24 \mathrm{~h}$ at a temperature of $37-40{ }^{\circ} \mathrm{C}$. In addition, Fig. 2 shows the change of $\mathrm{pH}$ in the medium according to the culture temperature, and measurements are shown in Fig. 2 according to the temperature. At $37{ }^{\circ} \mathrm{C}$, most proper $\mathrm{pH}$ for growing lactic acid bacteria as $\mathrm{pH} 5$ was maintained by comparing the $\mathrm{pH}$ of the medium under other culture temperature (Adamberg et al. 2003), which implied that most vital cells could be observed at the temperature between 37 and $40{ }^{\circ} \mathrm{C}$. These results could also tell that an optimum culture condition for this bacterium was $37^{\circ} \mathrm{C}$ and pH 5 . Figure 3 shows the SEM analysis for the morphological identification of the selected bacteria, and the new strain was identified as a rod-type lactic acid bacteria. Thereafter, the bacteria were amplified using PCR to analyze the $16 \mathrm{~S}$ rRNA to conclusively identify the strain.

\section{Analysis of the phylogenetic tree of the $16 \mathrm{~S}$ rRNA sequence of the new strain}

To identify the isolated strain, the base sequence of the $16 \mathrm{~S}$ rRNA gene was analyzed, and the results are shown in Table 1 . The analyzed base sequence was compared with the base sequences of similar strains registered in the GenBank database to examine the correlations between genes. Based on the results, the isolated strain had $55 \%$ homology with Lactobacillus paracasei subsp. Paracasei D79212. In addition, to determine the strain's molecular phylogenic relationship with the existing Lactobacillus group based on the structure of the 16S rRNA gene, a phylogenetic tree was prepared, and the results are shown in Fig. 3. The molecular phylogenic analysis also showed

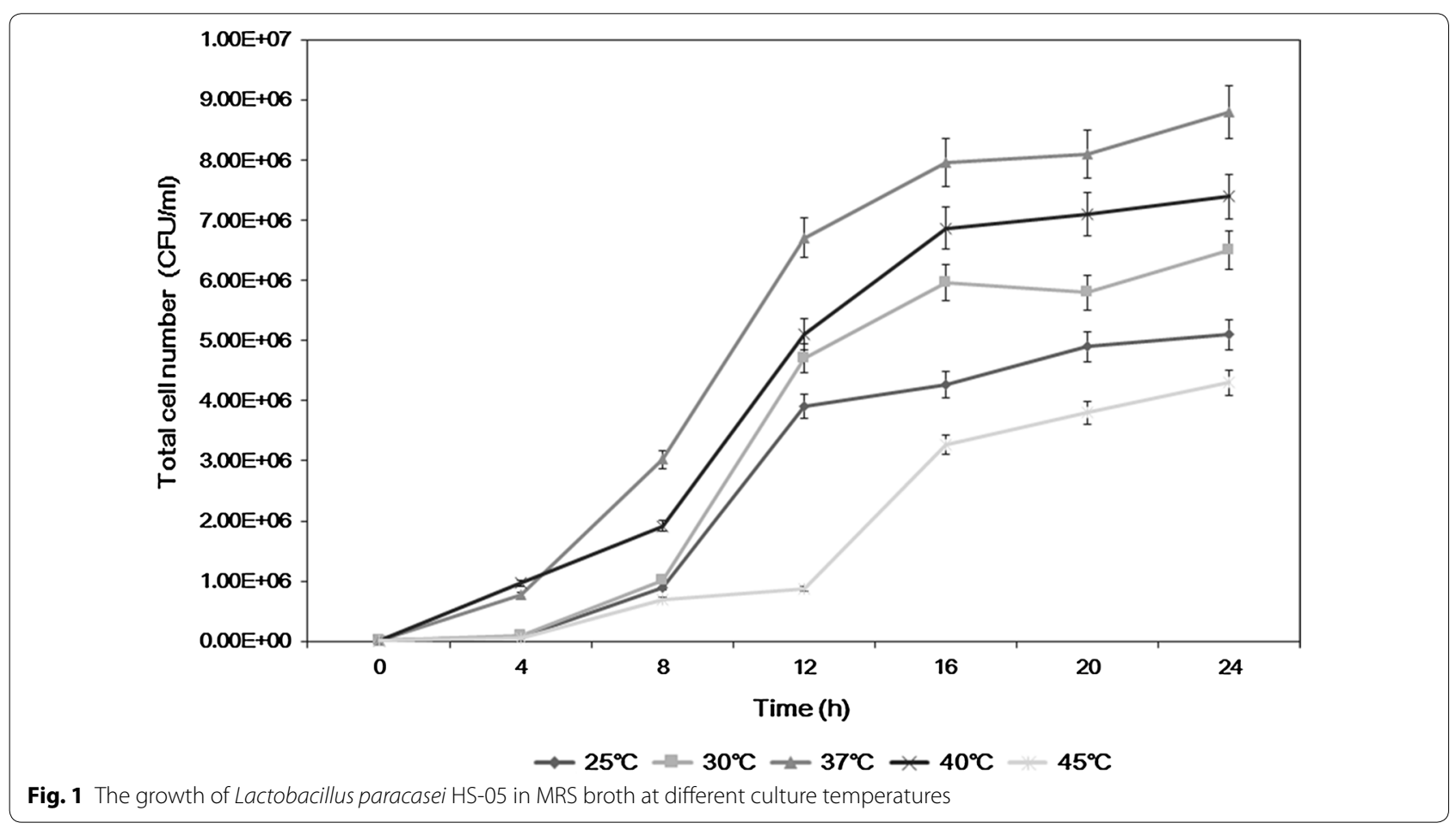




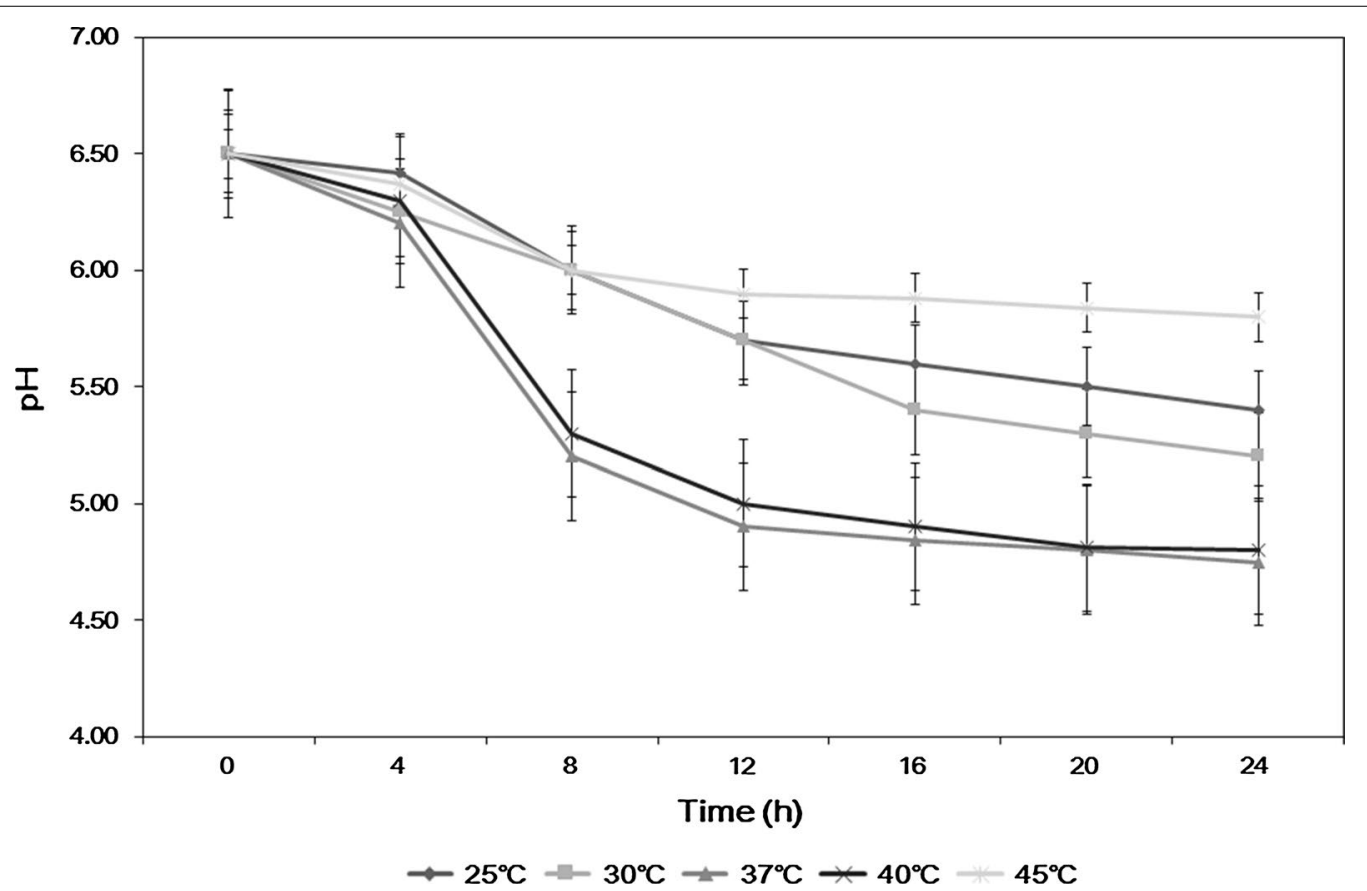

Fig. 2 pH changes of the culture broth of Lactobacillus paracasei HS-05 according to different culture temperatures
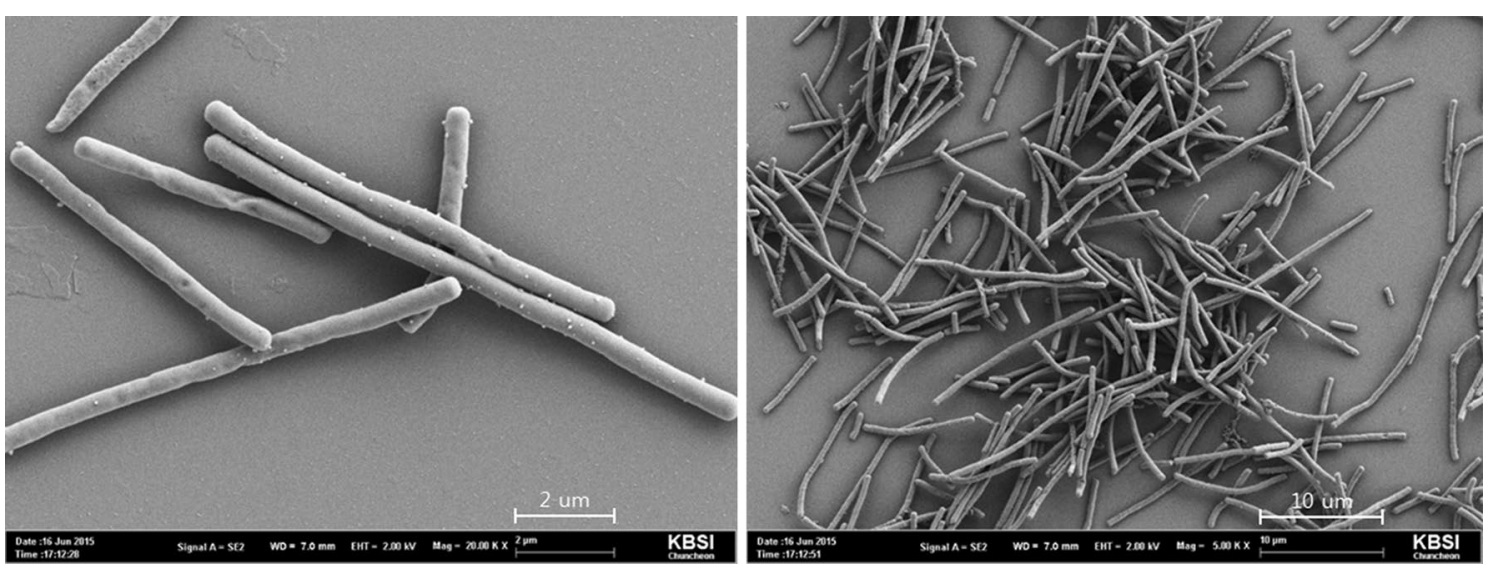

Fig. 3 A field emission scanning electron microscope (FE-SEM) image of Lactobacillus paracasei HS-05

that the isolated strain fell under the phylogenetic group that included Lactobacillus paracasei. Therefore, the lactic acid bacteria that was isolated from women's hands was named Lactobacillus paracasei HS-05 (Fig. 4).

\section{Discussion}

From this work, a human hand-derived lactic acid bacterium was successfully isolated. Although Proprionibacteria and Streptococcaceae are known to be present in large numbers on human skin, the Lactobacillaceae were found to be distributed in large numbers on the human hands (Fierera et al. 2008). In addition, more colonies were cultured from women's hands than from men's hands, and this is considered to be attributable to the fact that unlike the other types of common skin bacteria, the number of Lactobacillaceae are more variable and are not evenly distributed between men and women (Fierera et al. 2008). In particular, large numbers of colonies were observed for the hands of women in their $30 \mathrm{~s}$, which was considered to be due to the 
Table 1 The complete nucleotide sequence of the 16S rRNA from Lactobacillus paracasei HS-05

\section{HS-05}

AAGATTCTGTCAACAACGGTATCCATATGAGTTTGATCATGGCTCAGGAAGTCGTAACAAG GTGTCCATAGAGTTTGATCATGGCTCACGATATCTTAACACGGTGTCTCTATAGTTTGTGCT TGGCTCACAAAGACTCAACAACGGGTCGGTACATGTTTGAAATATGGGTAAGCTATCGCTT TTGGATGGACCCACGGCGTATTAGCTAGTTGGTGAGGTAATGGCTCACCAAGGCGATGATAC GTAGCCGAACTGAGAGGTTGATCGGCCACATTGGGACTGAGACACGGCCCAAACTCCTACG GGAGGCAGCAGTAGGGAATCTTCCACAATGGACGCAAGTCTGATGGAGCAACGCCGCGTGA GTGAAGAAGGCTTTCGGGTCGTAAAACTCTGTTGTTGGAGAAGAATGGTCGGCAGAGTAACT GTTGTCGGCGTGACGGTATCCAACCAGAAAGCCACGGCTAACTACGTGCCAGCAGCCGCGG TAATACGTAGGTGGCAAGCGTTATCCGGATTTATTGGGCGTAAAGCGAGCGCAGGCGCTTTT TTAAGTCTGATGTGAAAGCCCTCGGCTTAACCGAGGAAGCGCATCGGAAACTGGGAAACTT GAGTGCAGAAGAGGACAGTGGAACTCCATGTGTAGCGGTGAAATGCGTAGATATATGGAAG AACACCAGTGGCGAAGGCGGCTGTCTGGTCTGTAACTGACGCTGAGGCTCGAAAGCATGGGT AGCGAACAGGATTAGATACCCTGGTAGTCCATGCCGTAAACGATGAATGCTAGGTGTTGGA GGGTTTCCGCCCTTCAGTGCCGCAGCTAACGCATTAAGCATTCCGCCTGGGGAGTACGACCG CAAGGTTGAAACTCAAAGGAATTGACGGGGGCCCGCACAAGCGGTGGAGCATGTGGTTTAA TTCGAAGCAACGCGAAGAACCTTACCAGGTCTTGACATCTTTTGATCACCTGAGAGATCAG GTTTCCCCTTCGGGGGCAAAATGACAGGTGGTGCATGGTTGTCGTCAGCTCGTGTCGTGAGA TGTTGGGTTAAGTCCCGCAACGAGCGCAACCCTTATGACTAGTTGCCAGCATTTAGTTGGGC ACTCTAGTAAGACTGCCGGTGACAAACCGGAGGAAGGTGGGGATGACGTCAAATCATCATG CCCCTTATGACCTGGGCTACACACGTGCTACAATGGATGGTACAACGAGTTGCGAGACCGC GAGGTCAAGCTAATCTATTAAAGCCAATATCAGTTCAGGAGAGTAGGCTGCAACTCGCCTA CGTGAAATCGGAATCTCCAGAGAGTGCGAATCAGCATGACGAAGTGATAACAATGTCTCCC TAGAGTCAGATCACGGCTCAGCAAGTCGTAACAAGGTATCCATAGAGTTTGATCGAGGTCT CCAGCTAAAGTTCCG

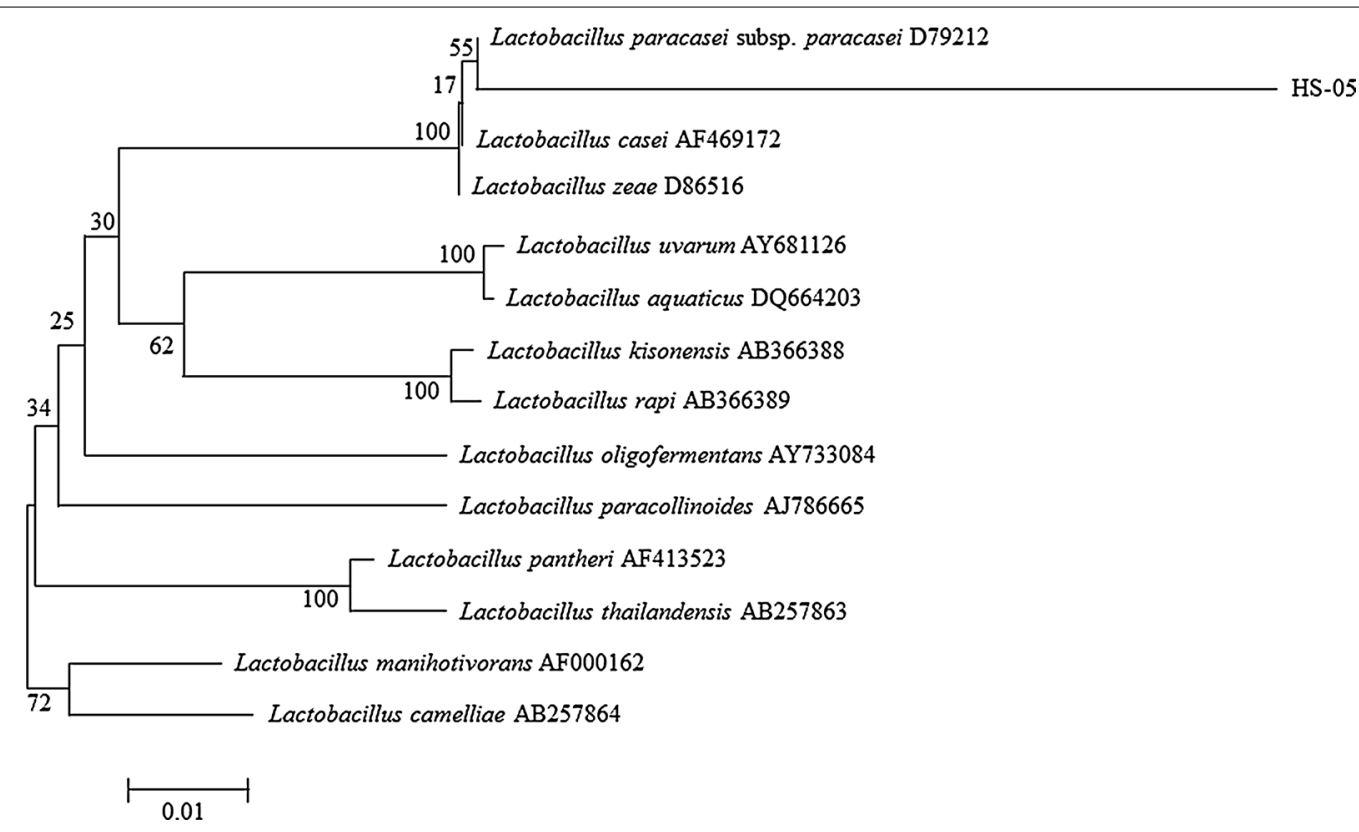

Fig. 4 The results of the phylogenetic tree analysis of Lactobacillus paracasei HS-05 based on 16S rRNA gene sequences

fact that their frequency of contact with cosmetics and/or foods is high (Costello et al. 2009; Dong et al. 2011). From the result of this work, Lactobacillus paracasei HS-05 was not found on men's hands but was found on women's hands. Moreover, it was also first confirmed that the bacterium profile and existence of
Lactobacillus paracasei HS-05 were not much affected by the personal histories and their job careers by having consistently high numbers of the colonies in most groups of women hands, not any kinds of men's hands. It is very interesting that the dominant existence of specific lactic acid bacterium was observed on the 
women and specially for young age women, regardless of their jobs, which could be further utilized for isolating other specific purpose bacterium from human body.

Lactobacillus paracasei HS-05 bacteria could be identified through a 16S rRNA analysis, as shown in Table 1, and no strain that has the same specific base sequence has been reported yet (Janda and Abbott 2007). Therefore, based on the 16S rRNA analysis and the molecular phylogenic analysis, the isolated strain was considered to fall under the phylogenic group that includes Lactobacillus, and had $99 \%$ homology with Lactobacillus paracasei subsp. Paracasei D79212. This is the first report of the existence of this strain on the hand surface of women, and this bacterium was thus named Lactobacillus paracasei HS-05 and has been registered in the Korea Culture Center of Microorganisms (KCCM) as [KCCM11349P].

\section{Authors' contributions}

WYC carried out the studies of analyzing microorgnisms and other related experiments, and HYL carried out the studies of identifying new microorganisms and drafted the manuscript. All authors read and approved the final manuscript.

\section{Author details}

${ }^{1}$ Department of Biomedical Materials Engineering, Kangwon National University, Chuncheon 200-701, Korea. ${ }^{2}$ Department of Food Science and Engineering, Seowon University, Cheongju 361-742, Korea.

\section{Acknowledgments}

This study was supported by a grant of the Korean Health Technology R\&D Project, Ministry of Health \& Welfare, Republic of Korea (Grant No. HN12C0060).

\section{Competing interests}

The authors declare that they have no competing interests.

\section{Ethics and consent}

All of the persons involved in this experiments were notified about this study and particiapted with their consent.

Received: 5 September 2015 Accepted: 31 October 2015

Published online: 10 December 2015

\section{References}

Adamberg K, Kask S, Laht TM, Paalme T (2003) The effect of temperature and $\mathrm{pH}$ on the growth of lactic acid bacteria: a pH-auxostat study. Int J Food Microbiol 85:171-183
Baek H, Ahn HR, Cho YS, Oh KH (2010) Antibacterial effects of Lactococcus lactis HK-9 isolated from feces of a new born infant. Korean J Microbiol 46:127-133

Choi WS, Kwon HS, Lim HW, No RW, Lee HY (2013) Whitening effects of Lactobacillus rhamnosus associated with its antioxidative activities. Korean $J$ Microbiol Biotechnol 41:183-189

Costello EK, Lauber CL, Hamady M, Fierer N, Gordon Jl, Knight R (2009) Bacterial community variation in human body habitats across space and time. Sci 326:1694-1697

Cotter PD, Hill C, Ross RP (2005) Bacteriocins: developing innate immunity for food. Nat Rev Microbiol 3:777-788

Dong Q, Brulc JM, lovieno A, Bates B, Garoutte A, Miller D, Revanna KV, Gao X, Antonopoulos DA, Slepak VZ, Shestopalov VI (2011) Diversity of bacteria at healthy human conjunctiva. Invest Ophthalmol Vis Sci 52:5408-5413

Fierera N, Hamady M, Lauber CL, Knight R (2008) The influence of sex, handedness, and washing on the diversity of hand surface bacteria. PNAS 105:17994-17999

Frederic L, Vuyst L (2004) Lactic acid bacteria as functional starter cultures for the food fermentation industry. Trends Food Sci Technol 15:67-78

Holo H, Nilssen Q, Nes IF (1991) Lactococcin A, a new bacteriocin from Lactococcus lactis subsp. cremoris: isolation and characterization of the protein and its gene. J Bacteriol 173:3879-3887

Jack RW, Tagg JR, Ray B (1995) Bacteriocins of grampositive bacteria. Microbiol Rev 59:171-200

Janda JM, Abbott SL (2007) 16S rRNA gene sequencing for bacterial identification in the diagnostic laboratory: pluses, perils, and pitfalls. J Clin Microbiol 45:2761-2764

Kojic M, Svircevic J, Banina A, Topisirovic L (1991) Bacteriocin-producing strain of Lactococcus lactis subsp. Diacitilactis S50. Appl Environ Microbiol 57:1835-1837

Lim YS, Kim SY, Lee SK (2008) Characteristics of lactic acid bacteria isolated from kefir made of goat milk. Korean J Food Sci Ani Resour 28:82-90

Maeng KJ, Kim JS, Ji GE, Kim JH (1997) Isolation of bacteriocin-producing lactic acid bacteria from human intestines and the characteristics or their bacteriocins. J Kor Food Sci Nutr 26:1228-1236

Marie A, Junelles R, Lefebvre G (1996) Purification and N-terminal amino acid sequence of dextranicin 24, a bacteriocin of Leuconostoc sp. Curr Microbiol 33:136-137

Petersen FC, Fimland G, Scheie AA (2006) Purification and functional studies of a potent modified quorum-sensing peptide and a two-peptide bacteriocin in Streptococcus mutans. Mol Microbiol 61:1322-1334

Schillinger U, Lucke FK (1989) Antibacterial activity of Lactobacillus sake isolated from meat. Appl Environ Microbiol 55:1901-1906

Todorov SD, Dicks LMT (2005) Characterization of bacteriocins produced by lactic acid bacteria isolated from spoiled black olives. J Basic Microbiol 45:312-322

Tomas MSJ, Ocana VS, Wiese B, Nader-Macias ME (2003) Growth and lactic acid production by vaginal Lactobacillus acidophilus CRL 1259, and inhibition of uropathogenic Escherichia coli. J Med Microbiol 52:1117-1124

Williams ST, Davies FL (1967) Use of a scanning electron microscope for the examination of actinomycetes. Microbiol 48:171-177

\section{Submit your manuscript to a SpringerOpen ${ }^{\circ}$ journal and benefit from:}

- Convenient online submission

- Rigorous peer review

- Immediate publication on acceptance

- Open access: articles freely available online

- High visibility within the field

- Retaining the copyright to your article

Submit your next manuscript at $>$ springeropen.com 